\title{
Structure determination of gas phase aluminum oxide clusters
}

\author{
D. van Heijnsbergen, ${ }^{a}$ K. Demyk, ${ }^{a}$ M. A. Duncan, ${ }^{b}$ G. Meijer ${ }^{a c}$ and G. von Helden*a \\ ${ }^{a}$ FOM-Institute for Plasma Physics Rijnhuizen, Edisonbaan 14, NL-3439 MN, Nieuwegein, \\ The Netherlands and Department of Molecular and Laser Physics, University of Nijmegen, \\ Toernooiveld, NL-6525 ED, Nijmegen, The Netherlands.E-mail: gertvh@rijnh.nl \\ ${ }^{b}$ Department of Chemistry, University of Georgia, Athens, Georgia 30602, USA \\ ${ }^{c}$ Fritz-Haber-Institut der Max-Planck-Gesellschaft, Faradayweg 4-6, D-14195, Berlin, \\ Germany
}

Received 24th December 2002, Accepted 14th April 2003

First published as an Advance Article on the web 12th May 2003

\begin{abstract}
Neutral aluminum oxide clusters are produced in a molecular beam by laser vaporization in a pulsed-nozzle cluster source. These clusters are ionized via (multi-) photon absorption from either an ultraviolet excimer laser or from a far-infrared free electron laser. Ultraviolet (multi-) photon ionization produces sparse mass spectra with only relatively light aluminum oxide clusters, while infrared ionization produces a smooth distribution of higher molecular weight ions from the same nascent source distribution. Tuning the IR wavelength, multiphoton infrared spectra are recorded pointing to the $\gamma-\mathrm{Al}_{2} \mathrm{O}_{3}$ structure for a whole series of $\mathrm{AlO} \cdot\left(\mathrm{Al}_{2} \mathrm{O}_{3}\right)_{n}$ clusters, $n \leq 34$.
\end{abstract}

\section{Introduction}

Since the first gas phase metal clusters were produced, a goal of their study has been the measurement of their structure and energetics as a function of size and the comparison of these properties to those of the corresponding solid material. Unfortunately, this goal is difficult to realize. Electronic structure as a function of cluster size has been probed extensively through ionization potential measurements, ${ }^{1}$ photoelectron spectroscopy, ${ }^{2}$ and photodissociation spectroscopy on plasmon resonances. ${ }^{3}$ However, obtaining information revealing the clusters' vibrational or geometric structure is much more difficult.

The fingerprint of a clusters' structure is hidden in its vibrational spectrum. Vibrational spectroscopy has been limited by the unavailability of tunable lasers in the required infrared wavelength region. Until recently, there has also been no technique sensitive and selective enough to measure vibrational spectra for specific clusters formed at low density in a distribution of sizes.

We have recently developed a technique called infrared resonance-enhanced multiphoton ionization (IR-REMPI) spectroscopy, ${ }^{4,5}$ making use of the unique properties of a tunable free-electron laser. ${ }^{6}$ It has been shown that this technique can provide size-specific vibrational spectroscopy for fullerenes ${ }^{4,5}$ and for metal-containing clusters. ${ }^{5,7-10}$

In this report, we are exploring the application of IRREMPI spectroscopy to the study of gas phase aluminum oxide clusters up to $c a$. 350 atoms in order to directly compare their vibrational features to those of the corresponding bulk material.

\section{A. Background on crystal structures of alumina}

Solid $\mathrm{Al}_{2} \mathrm{O}_{3}$ is a well-studied material with numerous applications. Under normal pressures and temperatures bulk aluminum oxide is crystallized as $\alpha-\mathrm{Al}_{2} \mathrm{O}_{3}$, better known as corundum. It is an insulator with a bandgap near $9 \mathrm{eV}$, which lowers to $7-8 \mathrm{eV}$ at the surface. ${ }^{11}$ It has a melting point around $2052^{\circ} \mathrm{C}$. Strong ionic bonding stabilizes the system which has an enthalpy of formation of $-256 \mathrm{~kJ} \mathrm{~mol}^{-1}$ at $298 \mathrm{~K}$.
Besides the thermodynamically most stable $\alpha-\mathrm{Al}_{2} \mathrm{O}_{3}$, many metastable $\mathrm{Al}_{2} \mathrm{O}_{3}$ polymorphs, also known as transition aluminas, exist. ${ }^{12}$ They can be divided into two broad categories: a face-centered cubic (fcc) or a hexagonal close-packed (hcp) arrangement of oxygen anions in the crystal. $\gamma-\mathrm{Al}_{2} \mathrm{O}_{3}, \theta$ $\mathrm{Al}_{2} \mathrm{O}_{3}$ (monoclinic), and $\eta-\mathrm{Al}_{2} \mathrm{O}_{3}$ (cubic) are examples of the former whereas $\alpha-\mathrm{Al}_{2} \mathrm{O}_{3}$ (trigonal) and $\kappa-\mathrm{Al}_{2} \mathrm{O}_{3}$ (orthorhombic) are examples of the latter. It is the distribution of the aluminum cations within each subgroup that results in the different polymorphs.

Small transition alumina particles have many applications in industry as adsorbents, coatings, and catalysts, because of their high surface area and catalytic activity. In order to manipulate their production and to understand the material's behavior when they undergo heat treatments, fundamental understanding is required about polymorphic phase transformations in the alumina crystal. This is for instance of major importance for the sintering of nanosized $\mathrm{Al}_{2} \mathrm{O}_{3}$ powders, which are usually $\gamma-\mathrm{Al}_{2} \mathrm{O}_{3}$ but transform during sintering to $\alpha-\mathrm{Al}_{2} \mathrm{O}_{3} \cdot{ }^{12}$ Both the sintering and the graingrowth behavior are strongly related to this phase transformation.

Whereas the structure of $\alpha-\mathrm{Al}_{2} \mathrm{O}_{3}$ is well-known ${ }^{13}$ (for instance by X-ray analysis), that of $\gamma-\mathrm{Al}_{2} \mathrm{O}_{3}$ is still the subject of much debate. Several studies have been documented, both experimental (X-ray photoelectron spectroscopy, ${ }^{14}$ ) and theoretical. ${ }^{15,16}$ It is commonly accepted that $\gamma-\mathrm{Al}_{2} \mathrm{O}_{3}$ has a defective spinel structure with a regular $\mathrm{ABCABC}$ packing of the oxygen anions and with tetrahedrally and octahedrally coordinated aluminum cations in-between. There is however disagreement on how the $8 / 3$ aluminum vacancies per unit-cell are distributed over the tetrahedral and octahedral sites, and this seems rather random (see Fig. 1). Because of this, the entropy of $\gamma-\mathrm{Al}_{2} \mathrm{O}_{3}$ is larger than that of $\alpha-\mathrm{Al}_{2} \mathrm{O}_{3}$ by $5.7 \mathrm{~J}$ $\mathrm{K}^{-1} \mathrm{~mol}^{-1} \cdot{ }^{17}$

It is commonly assumed that metastable structures like $\gamma$ $\mathrm{Al}_{2} \mathrm{O}_{3}$ and $\theta-\mathrm{Al}_{2} \mathrm{O}_{3}$ are adopted in order to lower the total energy of the material through a decrease in surface energy. Studies on nanocrystalline aluminas confirm that differences in surface energy can favor the formation of a particular 


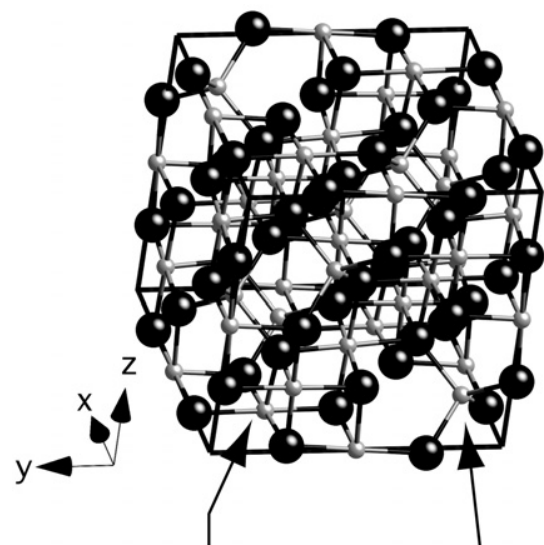

Octahedral site Tetrahedral site

Fig. 1 Model for the spinel structure of $\gamma-\mathrm{Al}_{2} \mathrm{O}_{3}$ with all the tetrahedral and octahedral cationic sites filled by $\mathrm{Al}$ atoms for clarity.

polymorph. More explicitly, it has been shown that nanocrystalline $\gamma-\mathrm{Al}_{2} \mathrm{O}_{3}$ can become thermodynamically stable at room temperature and atmospheric pressures at already relatively low limits of surface area per gram. ${ }^{17}$

The transformation of $\alpha-\mathrm{Al}_{2} \mathrm{O}_{3}$ into $\gamma-\mathrm{Al}_{2} \mathrm{O}_{3}$ and vice versa has been investigated thoroughly. Although this led to a better understanding and appreciation of the complexity of the process, many open questions remain. Electron diffraction studies ${ }^{12,18}$ have been carried out for many different polymorphs, but reflections occur mainly from the oxygen subcell, leaving it unclear which exact polymorph in the fcc and hcp classes of nanocrystalline aluminas plays a role in the transitions. It is not clear whether the $\gamma \rightarrow \alpha$ transition is a direct or an indirect (via other polymorphs) process. A model for the $\gamma \rightarrow \alpha$ phase transformation, however, has been developed, ${ }^{19}$ describing the rearrangement of stacking the oxygen ions in the lattice from fcc to hcp, thereby forcing some aluminum cations to change from their octahedral site to a tetrahedral position.

In the search for structural information of solid state aluminum oxide, the vibrational properties of thin $\mathrm{Al}_{2} \mathrm{O}_{3}$ films have been studied by several groups. ${ }^{20-22}$ Thin alumina films with a thickness of several $\AA$ (probably two Al-O layers) have been grown via oxidation of $\mathrm{NiAl}$ (110). Infrared spectra of these films exhibit clear and distinct features caused by lattice vibrations, which indicate a $\gamma-\mathrm{Al}_{2} \mathrm{O}_{3}$ crystalline structure. This is yet another example that $\alpha-\mathrm{Al}_{2} \mathrm{O}_{3}$ is not the thermodynamically most stable phase when the dimensions of the alumina material are on the nanoscale.

\section{B. Gas phase studies}

Only a limited number of studies on gas phase aluminum oxide clusters have been published. Most of these studies focus on clusters containing only a small number of aluminum and oxygen atoms. Lai-Sheng Wang and co-workers measured photoelectron spectra of gas phase $\mathrm{Al}_{x} \mathrm{O}_{y}{ }^{-}(x=1-2, y=1-5)$ clusters. ${ }^{23}$ Ground and excited electronic states were revealed and assigned, and for all the $\mathrm{Al}_{2} \mathrm{O}_{y}{ }^{-}(y=2-5)$ species the photoelectron spectrum was vibrationally resolved and analyzed. In addition, calculations were carried out at MP2 and HF levels of theory. Ortiz and co-workers extended the theoretical analysis by performing density functional (B3LYP) calculations, thereby being able to determine the gas phase geometry for some of these systems. ${ }^{24}$

Scott and co-workers studied hydration reactions of small aluminum oxide anion clusters ${ }^{25}$ and compared these to calculations using the HF, B3LYP, and MP2 levels of theory. Andrews et al. obtained infrared spectra for aluminum oxide clusters embedded in an argon matrix. ${ }^{26}$ Sharp absorptions were monitored belonging to several small aluminum oxide compounds. Bach and McElvany recorded ionization potentials of aluminum oxide molecules containing up to eight atoms by charge-transfer bracketing measurements in a FTICR mass spectrometer. ${ }^{27}$

The method used in the present experiments exploits the ability of strongly bound clusters to exhibit so-called "thermionic emission" of electrons following infrared multiphoton laser excitation..$^{4,5,7-9}$ Ionization in these clusters is competitive with other photoinduced processes such as dissociation because of their strong bonding and relatively low ionization potentials. Thermionic emission at fixed laser wavelengths has been observed for metal clusters, ${ }^{28}$ fullerenes ${ }^{29}$ and metal carbide clusters. ${ }^{30}$ Here, infrared resonance enhanced multi photon ionization (IR-REMPI) is obtained with a high fluence free electron laser in the infrared and far-IR wavelength region. ${ }^{31}$ It is based on the observation that thermionic emission is enhanced when the laser is resonant with an IR active vibrational mode. IR-REMPI was first described as a spectroscopic tool for gas phase clusters in the study of $\mathrm{C}_{60} \cdot{ }^{4}$ In later work, this method has been employed to study clusters produced in pulsed molecular beams by laser vaporization. Transition metal carbides and oxides have been studied to date with this method. ${ }^{7,8,10}$ We have recently extended this work to include main group metal oxides. ${ }^{9}$ In the present work, vibrational spectra for comparatively large $\mathrm{Al}_{2} \mathrm{O}_{3}$ clusters are discussed.

\section{Experimental}

Aluminum oxide clusters are produced in a molecular beam by laser vaporization from an aluminum rod in a pulsed nozzle source. The cluster source and the molecular beam machine for these experiments have been described previously. ${ }^{7}$ Material from a rotating sample rod (Al, $99.999 \%)$ is vaporized with the focused output of a Nd:YAG laser $(532 \mathrm{~nm})$ in an expansion of argon seeded with 1-5\% oxygen. The source employs a short-pulse gas valve (R. Jordan Co.) and a so-called waiting room section to enhance cluster formation. The cluster beam passes through a skimmer and enters a differentially pumped detection chamber, where it can be interrogated using a reflectron time-of-flight mass spectrometer (R. Jordan Co.). Cluster ions emitted directly from the source can be removed using deflection plates located upstream from the mass spectrometer. Neutral clusters are sampled after multiphoton ionization at $\mathrm{KrF}(248 \mathrm{~nm})$ or at ArF (193 nm) excimer laser wavelengths or after IR-REMPI with a tunable far-infrared free electron laser.

Infrared multiphoton ionization is accomplished with the free electron laser for infrared experiments (FELIX). ${ }^{6}$ The laser output comes in macropulses of $5 \mu$ s width at a repetition rate of $5 \mathrm{~Hz}$. Each macropulse contains a series of $0.3-5 \mathrm{ps}$ duration micropulses at a repetition rate of $1 \mathrm{GHz}$. A macropulse can contain up to $100 \mathrm{~mJ}$ of energy and the bandwidth is transform limited, ranging from $0.5 \%$ to several $\%$ FWHM. In the experiments reported here, a laser bandwidth of $c a .1 \%$ is used. The tuning range is $5-250 \mu \mathrm{m}\left(40-2000 \mathrm{~cm}^{-1}\right)$, although only the region from $5-25 \mu \mathrm{m}$ is used in the present experiments. The IR beam is focused on the molecular beam and fires at a time to intersect the molecular beam in the time-offlight source. A variable time delay after the IR laser pulse (typically $1-5 \mu \mathrm{s}$ ) is employed to allow ions formed via thermionic electron emission to accumulate. Then, the TOF acceleration plates are pulsed to high voltage to extract cations from the molecular beam into the TOF mass spectrometer. The ion signal is recorded with a digital oscilloscope (Yokogawa DL 4200) interfaced to a laboratory PC. Full TOF mass spectra are recorded at each FELIX laser wavelength while the laser is scanned. Subsequent data analysis can extract the wavelength dependence of any cluster mass (the IR-REMPI spectrum) or the mass spectrum at any wavelength. 


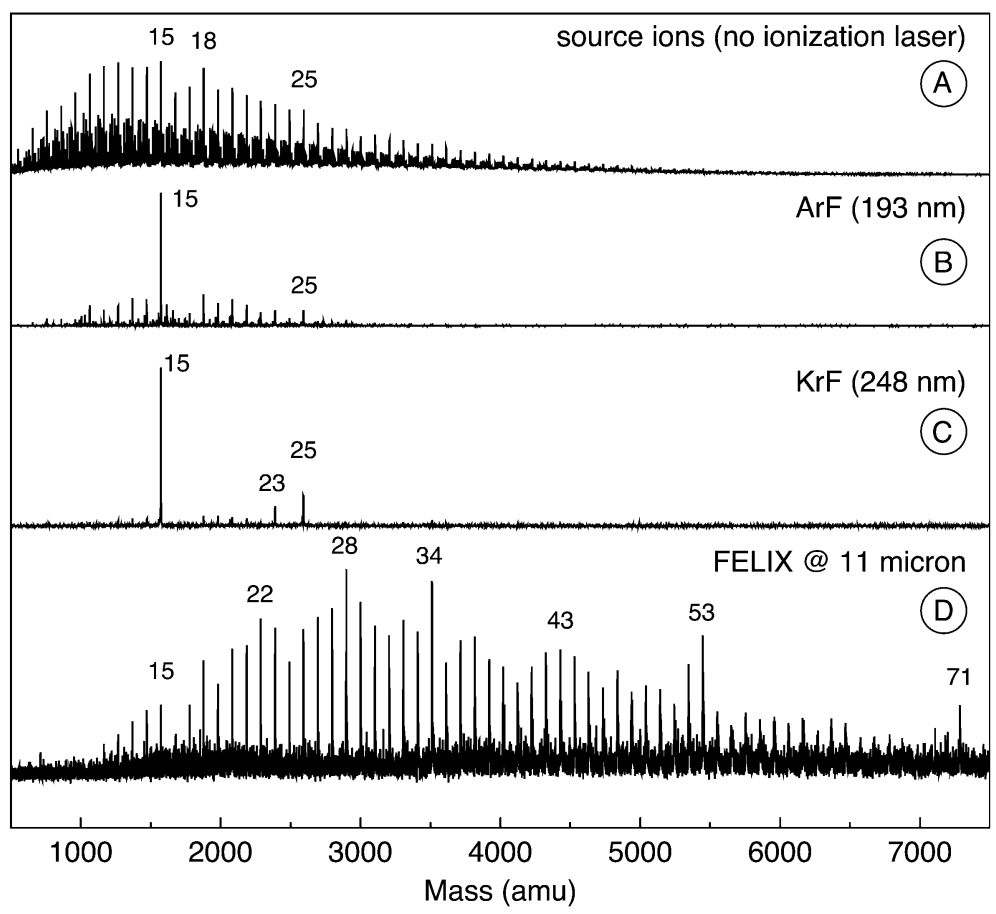

Fig. 2 Mass spectra of gas phase aluminum oxide clusters, photoionized with different photons under otherwise identical experimental conditions. The index number represents the number $n$ in $\mathrm{AlO} \cdot\left(\mathrm{Al}_{2} \mathrm{O}_{3}\right)_{n}$.

\section{Results and discussion}

Fig. 2 shows four mass spectra of cationic aluminum oxide clusters. The source conditions are kept the same throughout these measurements. Trace A is taken without any ionization laser at all, and represents cations emitted directly from the source. Most of the observed cluster ions can be identified as clustering of $\mathrm{Al}_{2} \mathrm{O}_{3}$ units in the stoichiometry $\mathrm{AlO} \cdot\left(\mathrm{Al}_{2} \mathrm{O}_{3}\right)_{n}$; the index number $n$ is given above the peaks in Fig. 2. Here, $n$ ranges from 5 to beyond 40 with all $n$ in-between clearly present. The distribution is overall rather smooth with the only remarkable feature a sudden decrease after $n=15$. The series of peaks in-between the $n$-units stem from aluminum- and/or oxygen-deficient structures.

In order to investigate the neutral species in the beam, a strong electric field $\left(1 \mathrm{kV} \mathrm{cm}{ }^{-1}\right)$ is used to eject the charged species $5 \mathrm{~cm}$ upstream from the laser-ionization region. Trace $\mathrm{B}$ is obtained when the molecular beam is then intersected with $193 \mathrm{~nm}$ (ArF) excimer laser photons $\left(6.4 \mathrm{eV}, 2-3 \mathrm{~mJ} \mathrm{~cm}^{-2}\right)$. The distribution of detected clusters is significantly different compared to trace A. This mass spectrum is dominated by the $n=15$ cluster, accompanied by some smaller clusters around it. Changing the ionization laser to $248 \mathrm{~nm} \mathrm{KrF}$ operation $\left(5.0 \mathrm{eV}, c a .10 \mathrm{~mJ} \mathrm{~cm}^{-2}\right)$ leads to a similar, however somewhat cleaner, mass spectrum, leaving essentially three masses at $n=15,23$, and 25 (trace C). Applying the IR light from FELIX at $11.0 \mu \mathrm{m}$ instead of the UV light from the excimer laser yields the mass spectrum shown in trace D. Now, a wide range of $\mathrm{AlO} \cdot\left(\mathrm{Al}_{2} \mathrm{O}_{3}\right)_{n}$ clusters is detected in the mass spectrum. Aluminum oxide clusters are observed from $n=11$ to $n=71$ with some peaks more prominent than others.

In all traces predominantly or solely the $\mathrm{AlO} \cdot\left(\mathrm{Al}_{2} \mathrm{O}_{3}\right)_{n}$ stoichiometries are detected. Ions produced directly in the source show other stoichiometries as well, but the intensity profile of this mass spectrum also clearly suggests a relatively high stability for the $\left[\mathrm{AlO} \cdot\left(\mathrm{Al}_{2} \mathrm{O}_{3}\right)_{n}\right]^{+}$species.

For mass spectra obtained using photoionization, ionization energetics play an additional role. The diatom AlO has an ionization potential (IP) of around $9.5 \mathrm{eV}^{32}$ whereas the IP of $\mathrm{Al}_{2} \mathrm{O}_{3}$ is $8.9 \mathrm{eV}^{27}$ and the energy required to remove an electron from bulk aluminum oxide is beyond $9 \mathrm{eV} .{ }^{33}$ Other aluminum oxide IP's are $8.35 \mathrm{eV}\left(\mathrm{Al}_{2} \mathrm{O}\right), 8.9 \mathrm{eV}\left(\mathrm{Al}_{2} \mathrm{O}_{2}\right)$, and $6.85 \mathrm{eV}\left(\mathrm{Al}_{2} \mathrm{O}_{4}\right){ }^{27}$ The fact that other stoichiometries with similar IP's of the constituents are not observed in the photo-ionized spectra can be explained in several ways. One possibility is that the cluster source does not produce neutral clusters with these alternative stoichiometries. This is unlikely since the source does produce them as ions (see trace A) and there is no obvious reason why they would not be present as neutrals. Another possibility is that these clusters are significantly less stable. Then, fragmentation in addition to ionization can occur leading to cleaner mass spectra only showing the more stable $\mathrm{AlO} \cdot\left(\mathrm{Al}_{2} \mathrm{O}_{3}\right)_{n}$ clusters.

Clearly, one cannot regard the $\mathrm{AlO} \cdot\left(\mathrm{Al}_{2} \mathrm{O}_{3}\right)_{n}$ clusters as a group of $\mathrm{Al}_{2} \mathrm{O}_{3}$ units and one extra $\mathrm{Al}-\mathrm{O}$ unit somewhere in the cluster. Instead, the clusters are likely to have an integrated "lattice-like" structure, represented by the stoichiometries mentioned before. Taking into account the oxidation states in the bulk ionic crystal $(+3$ for aluminum atoms and -2 for oxygen atoms) the cationic $\left[\mathrm{AlO} \cdot\left(\mathrm{Al}_{2} \mathrm{O}_{3}\right)_{n}\right]^{+}$is an electronically closed shell system for $n>0$. Therefore it is likely that the neutral $\mathrm{AlO} \cdot\left(\mathrm{Al}_{2} \mathrm{O}_{3}\right)_{n}$ clusters have a lower IP than other $\left(\mathrm{Al}_{2} \mathrm{O}_{3}\right)_{n}$ based stoichiometries. This then explains their dominance in all of the observed mass spectra.

As shown by the mass spectra of the "direct" ions from the source (A) and of the IR photoionized neutrals (D) the source produces a whole series of cationic and neutral $\mathrm{AlO} \cdot\left(\mathrm{Al}_{2} \mathrm{O}_{3}\right)_{n}$ clusters. Changing to UV ionization (B and $\mathrm{C}$ ), the recorded mass spectra change dramatically, probably due to (multiple) fragmentation in addition to ionization. Both UV laser ionized mass spectra are very similar, with the only difference that the slightly higher fluence for $\mathrm{KrF}$ relative to ArF leads to a more severe fragmentation of the clusters to yield the most stable structures. The high abundance of particularly the $n=15$ cluster suggests a geometrically closed-shell structure for this species.

The clusters observed in trace D have all absorbed many IR photons, which has been described and modeled previously, ${ }^{31}$ followed by thermionic electron emission. Fragmentation is expected to be negligible with the IR fluence applied here. ${ }^{7}$ 
This is consistent with the observed mass spectrum, which shows a very broad distribution of aluminum oxide clusters, comparable to the distribution of source ions in trace A. However, the center of the distribution has shifted from $n=15$ to roughly $n=34$. In the thermionic emission process the efficiency increases when the ionization potential (IP) decreases. In general, the IP is smaller for larger clusters with the same geometry, which might explain the bias towards larger species in trace D. The envelope of the mass spectrum in this trace is smooth and slightly oscillating, peaking at irregular intervals, probably indicative of geometric or electronic stability.

The IR induced thermionic emission process is highly wavelength dependent. In order to excite the clusters to high internal energies, the light needs to be in resonance with an IR active vibration. Evidently, IR radiation at $11.0 \mu \mathrm{m}$ is in resonance with such vibrations leading to the mass spectrum shown in Fig. 2D. To investigate the wavelength dependence of the thermionic emission process, FELIX is scanned over a broad range $(5-25 \mu \mathrm{m})$. Monitoring the ion yield of each mass as a function of the wavelength results in the infrared spectrum of the corresponding cluster.

The infrared spectra are shown in Fig. 3 in the range from 9 to 20 micron. Outside of this region, no ion signal is observed for any of the species. For clusters with $n=15$, the IR spectrum shows a resonance at $11.0 \mu \mathrm{m}$, although it is fairly weak. For larger clusters, a second resonance around $16.0 \mu \mathrm{m}$ appears, as seen in the spectra for $n=25,28$ and 34. Both the resonances at 11.0 and 16.0 micron do not shift significantly with size. At $n=34$, the valley between the two resonances slowly begins to disappear. For $n=53$ and 62 the spectra then evolve into a single broad band from 11 to 17 micron. Because all of the observed clusters in Fig. 2D exhibit a similar response to the IR radiation, only the spectra of the selected clusters are displayed to show the trend.

Since the IR-REMPI technique relies on a highly non-linear multiple-photon absorption process, the observed relative intensities are not necessarily a correct measure for the relative

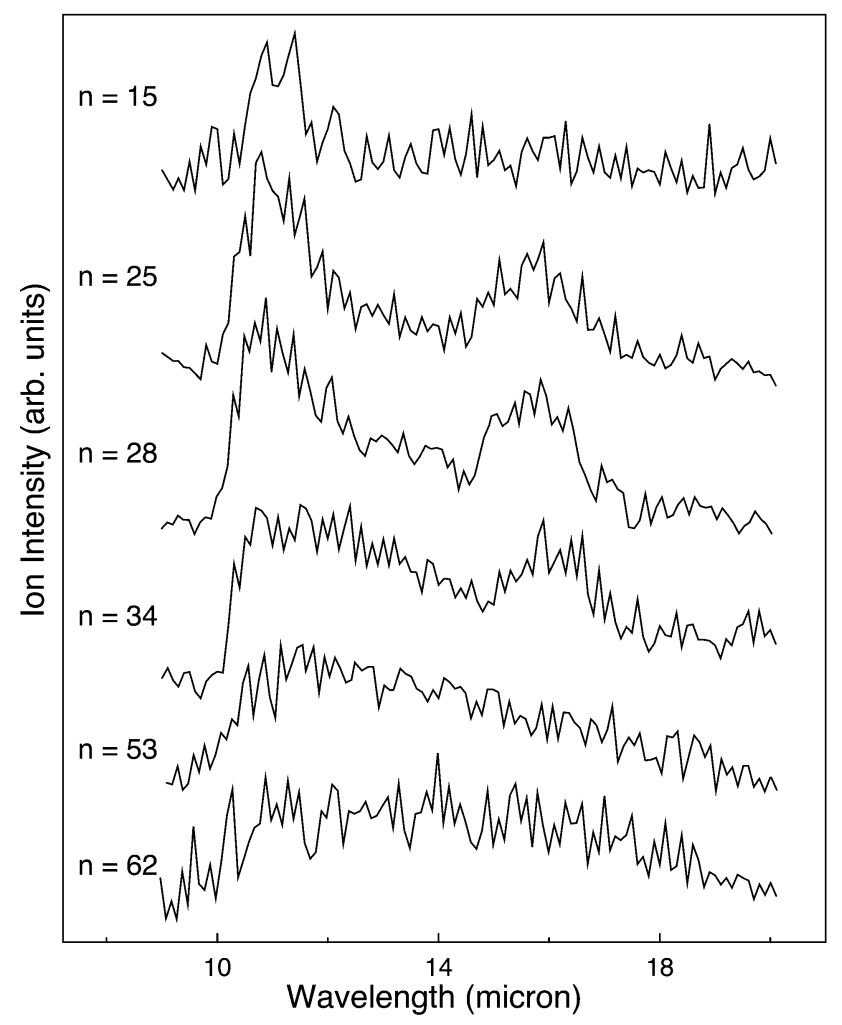

Fig. 3 Infrared resonance enhanced multi-photon ionization (IRREMPI) spectra of several neutral aluminum oxide clusters. The index number represents the number $n$ in $\mathrm{AlO} \cdot\left(\mathrm{Al}_{2} \mathrm{O}_{3}\right)_{n}$. oscillator strengths of the modes. For $n=15$, the IR-REMPI signal is weak and only a mode at $11.0 \mu \mathrm{m}$ is observed. As we observe the $16.0 \mu \mathrm{m}$ mode for $n=25$ and 28 it cannot be excluded that the $16.0 \mu \mathrm{m}$ mode is present for $n=15$ as well but that it is too weak to be detected there. For $n=25,28$, and 34 , the infrared spectra are rather similar, independent of their size. Although rather surprising, this has been observed for other families of metal carbide and oxide clusters as well. ${ }^{9,34}$ For the heavier aluminum oxide clusters, the IRREMPI signals become weaker again. However, the infrared spectra for $n=53$ and 62 display a different behavior than for $n=15$; the appearance of a broad, unstructured absorption feature could indicate a structurally different cluster.

It should be noted that this evolution to a broad band can depend on the source conditions. Adjusting experimental parameters such as ablation laser intensity, backing pressure of the pulsed valve, and timing can delay or accelerate this phenomenon in terms of cluster size. Details as well as other aspects such as the astrophysical relevance of these oxide clusters will be discussed elsewhere. ${ }^{35}$

Unfortunately, no other gas phase spectroscopic measurements have been carried out in this wavelength region for any of these aluminum oxide clusters nor do theoretical calculations exist, which could provide insight into the nature of the vibrational modes observed. It has been shown before that vibrations of gas phase clusters can match those of solid state samples very well. ${ }^{10}$ However, as mentioned in the introduction, IR studies have been carried out for the single $\mathrm{Al}_{2} \mathrm{O}_{3}$ molecule ${ }^{23,26}$ as well as on ultrathin solid state samples ${ }^{21,22}$ to which the data obtained here can be compared. In addition, one can derive the infrared response of small $\mathrm{Al}_{2} \mathrm{O}_{3}$ particles using the Mie theory ${ }^{36}$ based on the known optical constants. ${ }^{37}$

Fig. 4 shows five traces, of which trace A and D are the IRREMPI spectra for the $n=28$ and the $n=53$ cluster, respectively, copied from Fig. 3. Trace $\mathrm{C}$ and $\mathrm{E}$ are spectra derived from the optical constants of bulk aluminum oxide for spherical particles in the Rayleigh limit (i.e. small compared to the wavelength), via a method described by Bohren and Huffman. ${ }^{36}$ Trace $\mathrm{C}$ represents the spectrum of solid crystalline

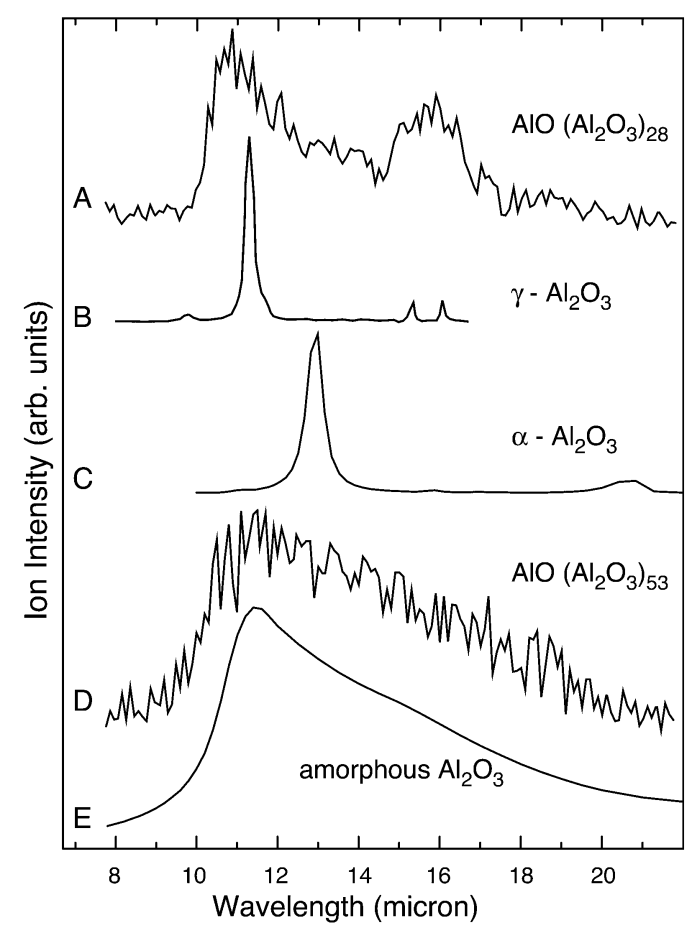

Fig. 4 Comparison of gas phase vibrational spectra for $n=28$ (A) and for $n=53$ (D) to known IR absorption spectra in several different bulk aluminum oxide lattices $\left(\mathrm{B}=\gamma-\mathrm{Al}_{2} \mathrm{O}_{3} ; \mathrm{C}=\alpha-\mathrm{Al}_{2} \mathrm{O}_{3} ; \quad \mathrm{E}=\right.$ amorphous $\mathrm{Al}_{2} \mathrm{O}_{3}$ ). 
$\alpha-\mathrm{Al}_{2} \mathrm{O}_{3}$, whereas trace $\mathrm{E}$ describes the IR properties of amorphous aluminum oxide. Trace $\mathrm{B}$ is taken from an ultrathin (roughly $2 \mathrm{Al}-\mathrm{O}$ layers) solid state $\gamma-\mathrm{Al}_{2} \mathrm{O}_{3}$ film grown on a $\mathrm{NiAl}$ (110) surface, as reported by Freund and co-workers. ${ }^{21}$ The optical constants of bulk $\gamma-\mathrm{Al}_{2} \mathrm{O}_{3}$ are yet to be determined.

An IR active molecular vibration of $\mathrm{Al}_{2} \mathrm{O}_{3}$ is observed at 11.8 micron, ${ }^{23}$ compatible with all of the observed spectra. When comparing the IR-REMPI spectrum of small (around $n=15$ ) $\mathrm{AlO} \cdot\left(\mathrm{Al}_{2} \mathrm{O}_{3}\right)_{n}$ clusters (trace A) to IR spectra based on bulk optical constants (trace $\mathrm{C}$ and $\mathrm{E}$ ) or ultrathin material $\left(\gamma-\mathrm{Al}_{2} \mathrm{O}_{3}\right.$, trace $\left.\mathrm{B}\right)$, it is clear that the best match is with that of $\gamma-\mathrm{Al}_{2} \mathrm{O}_{3}$. The overall agreement between the two spectra is quite remarkable. The gas phase spectrum in trace $\mathrm{A}$ is clearly different from that of crystalline $\alpha-\mathrm{Al}_{2} \mathrm{O}_{3}$ (trace $\mathrm{C}$ ). The number of modes agrees, however there is a considerable shift in position.

The larger $\mathrm{AlO} \cdot\left(\mathrm{Al}_{2} \mathrm{O}_{3}\right)_{n}$ clusters $(n>34)$ exhibit different spectra than the smaller ones. Their spectra (trace $\mathrm{D})$ are more similar to spectra of amorphous $\mathrm{Al}_{2} \mathrm{O}_{3}$. This is supported by the observation of a spectrum similar to trace D and E in alumina coated boron nitride particles, ${ }^{38}$ where TEM images revealed the amorphous structure of the alumina.

\section{Conclusion}

Gas phase aluminum oxide clusters are produced and analyzed in a molecular beam spectrometer. Mass spectra of ions created by the cluster source, UV ionized neutral clusters, or IR ionized neutral clusters all show that they grow by the addition of $\mathrm{Al}_{2} \mathrm{O}_{3}$ units. In addition to ionization, UV irradiation causes significant fragmentation. Worth mentioning in this respect is the large abundance of the $\mathrm{AlO} \cdot\left(\mathrm{Al}_{2} \mathrm{O}_{3}\right)_{15}$ cluster ion in the mass spectra, suggesting a stable structure with a geometric and/or electronic closed-shell configuration for this species.

Making use of the infrared laser facility "FELIX", infrared spectra are obtained for a whole series of $\mathrm{AlO} \cdot\left(\mathrm{Al}_{2} \mathrm{O}_{3}\right)_{n}$ clusters with $n$ ranging from 11 to 71 . All of these spectra have similar features that gradually change when going to larger clusters. For clusters up to $n=34$, two peaks are observed at 11.0 and $16.0 \mu \mathrm{m}$. Comparing this to known IR features of different solid state aluminum oxide lattices clearly identifies these gas phase clusters to have a structure similar to $\gamma-\mathrm{Al}_{2} \mathrm{O}_{3}$ instead of $\alpha$ $\mathrm{Al}_{2} \mathrm{O}_{3}$, which is the thermodynamically stable form of the bulk at normal pressures and temperatures. Since these two polymorphs belong to different arrangements of the oxygen anions in the lattice $\left(\gamma-\mathrm{Al}_{2} \mathrm{O}_{3}\right.$ is fcc while $\alpha-\mathrm{Al}_{2} \mathrm{O}_{3}$ is hcp), chemical and physical properties such as the vibrational spectrum are rather different, allowing us to distinguish between these. However, transition aluminas in the same fcc or hcp category are much more difficult to distinguish. $\theta-\mathrm{Al}_{2} \mathrm{O}_{3}$, for instance, is structurally very close to $\gamma-\mathrm{Al}_{2} \mathrm{O}_{3}$. They are both monoclinic crystals, and have virtually the same bond angles and bond lengths. ${ }^{20}$ The only difference is the statistical occupation of the octahedral and tetrahedral vacancies in the lattice. Therefore, the experimental data presented here cannot discriminate between these different polymorphs in the same category.

Aluminum oxide clusters larger than $n=34$ exhibit one broad band between 11 and 17 micron. Among other possibilities this could be caused by the build-up of amorphous aluminum oxide clusters, which is supported by the resemblance of the spectra for these clusters to the IR response of bulk amorphous $\mathrm{Al}_{2} \mathrm{O}_{3}$.

\section{Acknowledgements}

We gratefully acknowledge the support by the "Stichting voor Fundamenteel Onderzoek der materie" (FOM) in providing the required beam time at FELIX and greatly appreciate the skilful assistance of the FELIX staff. This work is part of the research program of FOM, which is supported financially by the "Nederlandse Organisatie voor Wetenschappelijk Onderzoek
(NWO)". MAD acknowledges support from the US Air Force Office of Scientific Research grant No. F49620-00-1-0118.

\section{References}

1 M. Seidl, K. H. Meiwes-Broer and M. Brack, J. Chem. Phys, 1991, 95, 1295

2 H. Wu, S. R. Desai and L. S. Wang, Phys. Rev. Lett., 1996, 77, 2436.

3 W. A. de Heer, K. Selby, V. Kresin, J. Masui, M. Vollmer, A. Chatelain and W. D. Knight, Phys. Rev. Lett., 1987, 59, 1805.

4 G. von Helden, I. Holleman, G. M. H. Knippels, A. F. G. van der Meer and G. Meijer, Phys. Rev. Lett., 1997, 79, 5234.

5 G. von Helden, D. van Heijnsbergen and G. Meijer, J. Phys. Chem. A, 2003, 107, 1671 .

6 D. Oepts, A. F. G. van der Meer and P. W. van Amersfoort, Infrared Phys. Technol., 1995, 36, 297.

7 D. van Heijnsbergen, G. von Helden, M. A. Duncan, A. J. A. van Roij and G. Meijer, Phys. Rev. Lett., 1999, 83, 4983.

8 G. von Helden, A. Kirilyuk, D. van Heijnsbergen, B. Sartakov, M. A. Duncan and G. Meijer, Chem. Phys., 2000, 262, 31.

9 D. van Heijnsbergen, G. von Helden, G. Meijer and M. A. Duncan, J. Chem. Phys., 2002, 116, 2400.

10 D. van Heijnsbergen, A. Fielicke, G. Meijer and G. von Helden, Phys. Rev. Lett., 2002, 89, 13401.

11 M. Gautier, G. Renaud, L. Van Pham, B. Villette, M. Pollak, N. Thromat, F. Jollet and J. P. Duraud, J. Am. Ceram. Soc., 1994, 77, 323 .

12 I. Levin and D. Brandon, J. Am. Ceram. Soc., 1998, 81, 1995.

13 J. B. Bilde-Sørensen, B. F. Lawlor, T. Geipel, P. Pirouz, A. H. Heuer and K. P. D. Lagerlöf, Acta Metall. Mater., 1996, 44, 2145.

14 B. Ealet, M. H. Elyakhlouf, E. Gillet and M. Ricci, Thin Solid Films, 1994, 250, 92.

15 S.-D Mo, Y.-N Xu and W.-Y Ching, J. Am. Ceram. Soc., 1997, 80, 1193.

16 G. Gutiérrez, A. Taga and B. Johansson, Phys. Rev. B, 2002, 65, 12101.

17 J. M. McHale, A. Auroux, A. J. Perrotta and A. Navrotsky, Science (London), 1997, 277, 788.

18 T. C. Chou and T. G. Nieh, J. Am. Ceram. Soc., 1991, 74, 2270.

19 S. Kachi, K. Momiyama and S. Shimuzu, J. Phys. Soc. Jpn., 1963 , 18, 106.

20 R. Franchy, Surf. Sci. Rep., 2000, 38, 195.

21 M. Frank, K. Wolter, N. Magg, M. Heemeier, R. Kühnemuth, M. Bäumer and H. J. Freund, Surf. Sci., 2001, 492, 270.

22 M. B. Lee, J. H. Lee, B. G. Frederick and N. V. Richardson, Surf. Sci., 2000, 448, L207.

23 S. R. Desai, H. Wu, C. M. Rohlfing and L.-S Wang, J. Chem. Phys., 1997, 106, 1309.

24 A. Martínez, F. J. Tenorio and J. V. Ortiz, J. Phys. Chem. A, 2001, 105, 11291.

25 J. R. Scott, G. S. Groenewold, A. K. Gianotto, M. T. Benson and J. B. Wright, J. Phys. Chem. A, 2000, 104, 7079.

26 L. Andrews, T. R. Burkholder and J. T. Yustein, J. Phys. Chem., 1992, 96, 10182

27 S. B. H. Bach and S. W. McElvany, J. Phys. Chem., 1991, 95, 9091 .

28 A. Amrein, R. Simpson and P. Hackett, J. Chem. Phys., 1991, 95, 1781 .

29 P. Wurz and K. R. Lykke, J. Chem. Phys., 1991, 95, 7008.

30 S. F. Cartier, B. D. May and A. W. Castleman, Jr., J. Chem. Phys., 1995, 104, 3423.

31 G. von Helden, I. Holleman, G. Meijer and B. Sartakov, Opt. Express, 1999, 4, 46.

32 P. B. Armentrout, L. F. Halle and J. L. Beauchamp, J. Chem. Phys., 1982, 76, 2449.

33 S. Andersson, P. A. Brühwiler, A. Sandell, M. Frank, J. Libuda, A. Giertz, B. Brena, A. J. Maxwell, M. Bäumer, H. J. Freund and N. Mårtensson, Surf. Sci., 1999, 442, L964.

34 G. von Helden, A. G. G. M. Tielens, D. van Heijnsbergen, M. A. Duncan, S. Hony, L. B. F. M. Waters and G. Meijer, Science (London), 2000, 288, 313.

35 K. Demyk, D. van Heijnsbergen, G. von Helden and G. Meijer, to be published.

36 C. F. Bohren and D. R. Huffman, Absorption and Scattering of Light by Small Particles, Wiley-Interscience, New York, paperback series published 1998.

37 M. W. Ribarsky Handbook of Optical Constants of Solids, Academic Press, New York, 1985.

38 J. D. Ferguson, A. W. Weimer and S. M. George, Thin Solid Films, 2000, 371, 95. 